\title{
Identification and characterization of peroxisome proliferator response element in the mouse GLUT2 promoter
}

\author{
Seung-Soon $\operatorname{Im}^{1,2,4}$, Jae-Woo Kim ${ }^{1,3}$, \\ Tae-Hyun Kim ${ }^{1,2,4}$, Xian-Li Song ${ }^{1,2,4}$, \\ So-Youn $\mathrm{Kim}^{1,2,4}, \mathrm{Ha}-\mathrm{il} \mathrm{Kim}^{1}$ and \\ Yong-Ho $\mathrm{Ahn}^{1,2,4,5}$ \\ ${ }^{1}$ Department of Biochemistry and Molecular Biology \\ ${ }^{2}$ Center for Chronic Metabolic Disease Research \\ ${ }^{3}$ Institute of Genetic Science \\ ${ }^{4}$ Brain Korea 21 Project for Medical Science, Korea \\ Yonsei University College of Medicine \\ 134 Sinchon-dong, Seodaemun-gu \\ Seoul 120-752, Korea \\ ${ }^{5}$ Corresponding author: Tel, 82-2-361-5183; \\ Fax, 82-2-312-5041; E-mail, yha111@yumc.yonsei.ac.kr
}

Accepted 16 March 2005

Abbreviations: ChIP assay, chromatin immunoprecipitation assay; EMSA, electrophoretic mobility shift assay; GLUT2, glucose transporter type 2; PPAR, peroxisome proliferator-activated receptor; PPRE, peroxisome proliferator response element; RXR, retinoid $X$ receptor

\begin{abstract}
In the present study, we show that the expres. sion of type 2 glucose transporter isoform (GLUT2) could be regulated by PPAR- $\gamma$ in the liver. Rosiglitazone, PPAR- $\gamma$ agonist, activated the GLUT2 mRNA level in the primary cultured hepatocytes and Alexander cells, when these cells were transfected with PPAR- $/$ RXR- $\alpha$. We have localized the peroxisome proliferator response element in the mouse GLUT2 promoter by serial deletion studies and site-directed mutagenesis. Chromatin immunoprecipitation assay using ob/ob mice also showed that PPAR- $\gamma$ rather than PPAR- $\alpha$ binds to the $-197 /-184$ region of GLUT2 promoter. Taken together, liver GLUT2 may be a direct target of PPAR $-\gamma$ ligand contributing to glucose transport into liver in a condition when PAPR- $\gamma$ expression is increased as in type 2 diabetes or in severe obesity.
\end{abstract}

Keywords: GLUT2; liver; promoter; PPAR- $\gamma$; rosiglitazone; type 2 diabetes

\section{Introduction}

Recently, peroxisome proliferator-activated receptor (PPAR) family draws much attention in the treatment of type 2 diabetes. Three isoforms, encoded by separate genes, have been identified so far: PPAR- $\alpha$, PPAR- $\beta(\delta)$, and PPAR- $\gamma$ (Sher et al., 1993). PPAR- $\alpha$ is highly expressed in hepatocytes, enterocytes, proximal tubular epithelium of kidney, and cardiac muscle, and the expression pattern parallels, to a certain extent, the sensitivity of various tissues to the $\beta$-oxidation induction by synthetic peroxisome proliferators (Spiegelman, 1998; Guillemain et al., 2000). PPAR- $\gamma$ is known to be involved in adipogenesis, and maintenance of differentiation is important in breast, colon, and urinary bladder function. PPAR- $\gamma$ is a member of the nuclear hormone receptors that contains the ligand-dependent activation domain (AF-2) (Picard et al., 2002). Upon ligand binding, PPAR- $\gamma$ heterodimerized with retinoid $X$ receptor $(R X R)-\alpha$ binds to the PPAR response element (PPRE) and activates target gene transcription. Thiazolidinediones (TZDs) are a class of antidiabetic agents that improve insulin sensitivity in various animal models of diabetes (Cavaghan et al., 1997; Rahimian et al., 2001). Patients with a dominant-negative mutation in the PPAR- $\gamma$ gene show severe hyperglycemia, which provides a genetic link between PPAR- $\gamma$ and type 2 diabetes (Barroso et al., 1999). So far, a mechanism of antihyperglycemic effect of TZDs on the liver is considered to be rather indirect (Jiang et al., 2002), partly because hepatic expression of PPAR- $\gamma$ is rather low, and adipocytes specific deletion of the PPAR- $\gamma$ gene affects the blood glucose level (He et al., 2003). However, in the pathological state, as in obesity and type 2 diabetes patients, the expression of PPAR- $\gamma$ is known to be increased (Rahimian et al., 2001). Thus, the direct role of PPAR- $\gamma$ ligand on the genes involved in hepatic glucose metabolism cannot be ruled out. Previously, we have characterized the peroxisom proliferator-activator response element (PPRE) in the promoter regions of rat GLUT2 (Kim et al., 2000) and glucokinase (Kim et al., 2002) gene and reported their physiological implications in the insulin secretion in response to changing blood glucose level in the pancreas of type 2 diabetic Zucker diabetic fatty (ZDF) rats. We also showed that liver type glucokinase (LGK) was directly upregulated by TZDs in its promoter (Kim et al., 2004). Because L-GK functions very closely with GLUT2 in transporting glucose into liver, it is possible that TZDs can activate both GLUT2 and L-GK gene in a coordinate manner.

To explore this possibility, we have dissected mouse GLUT2 promoter and identified a PPRE in the $-197 /-184$ region. We also demonstrated that PPAR- $\alpha$ 
is not a good inducer of GLUT2 expression whereas PPAR- $\gamma$ stimulated the endogenous GLUT2 mRNA expression in primary mouse hepatocytes when PPAR$\gamma$ was ectopically expressed. Also, in the liver of $o b /$ ob mice, where PPAR- $\gamma$ expression is increased (Edvardsson et al., 1999), the PPAR- $\gamma$ ligand upregulated the GLUT2 expression whereas PPAR- $\alpha$ ligand did not affect its expression, indicating that PPAR- $\gamma$ may contribute to lowering blood glucose level by activating GLUT2 gene expression in the diabetic liver.

\section{Materials and Methods}

\section{Materials}

Wy14,643 $(20 \mathrm{mM}$ in $19 \%$ BSA and $5 \%$ dimethyl sulfoxide), 9-cis retinoic acid (2 $\mathrm{mM}$ in $50 \%$ ethanol and $50 \%$ dimethyl sulfoxide), and rosiglitazone (2 $\mathrm{mM}$ in $5 \%$ BSA and $5 \%$ dimethly sulfoxide) were diluted to the final concentration of $20 \mu \mathrm{M}, 1 \mu \mathrm{M}$, and $2 \mu \mathrm{M}$ respectively. Wy14,643 and 9-cis retinoic acid were purchased from Sigma-Aldrich (St. Louis, MO). Rosiglitazone was kindly donated by GlaxoSmithKline, UK. PPAR $-\alpha$ and PPAR $-\gamma$ antibodies were purchased from PPMX Perseus Proteomics Inc, Japan.

\section{Construction of plasmids}

The promoter region $(-1112 /+1)$ of the mouse GLUT2 gene was cloned into the Kpnl/Xhol site of the pGL3basic vector (Promega, Madison, WI) to generate pMGT2-1112. Deletion constructs of mouse GLUT2 promoter were prepared from pMGLUT2 (pMGT2-1112/ +1). pMGT2d-890 was prepared by excising out 222 bp fragment of Sall and EcoRI digestion. pMGT2d389 was constructed by digesting with Sall and Pstl from the pMGT2-1112/+1. Other deletion constructs of mouse GLUT2 promoter were prepared by digesting pMGT2-1112/+1 after EcoRI sites was generated by PCR-based site-directed mutagenesis kit (Stratagene, La Jolla, CA), and named pMGT2d-283, pMGT2d-166, and pMGT2d-57, respectively. The PPRE truncated construct, pMGT2d-283/-166, was also prepared from pMGT2d-389 with the same method described above. Mutant constructs pMGT2m-389mut1 (mut1), pMGT2m389 mut2 (mut 2), and pMGT2m-389mut1+2 (mut1+2) were produced by introducing substitution mutations into pMGT2d-389 using site-directed mutagenesis. The sequences of constructs were confirmed by dideoxyDNA sequencing method. Expression plasmids, pCMXmPPAR- $\alpha$, pCMX-mPPAR- $\gamma$ and pCMX-mRXR- $\alpha$ were kind gifts from Drs. R. M. Evans and D. J. Mangelsdorf (Mangelsdorf et al., 1992; Kliewer et al., 1994). Control vector, $\mathrm{pCMX}$ was prepared from $\mathrm{pCMX}$ mRXR- $\alpha$ by excising out the $1.5 \mathrm{~kb}$ fragment of $m R X R-\alpha$ cDNA. The dominant negative plasmid of NF-Y ( $\triangle$ 4NF-YA13m29; NF-Ym) was provided by $\mathrm{Dr}$. R. Mantovani (Gurtner et al., 2003).
Primary hepatocytes preparation from mouse liver Hepatocytes were isolated from male ICR mouse (approximately $30 \mathrm{~g}$ ) by the collagenase perfusion method (Seglen, 1972). Dissociation into individual hepatocytes was performed in Dulbecco's modified Eagles' medium (DMEM) containing $10 \%(\mathrm{v} / \mathrm{v})$ heat inactivated fetal calf serum (FCS), $0.1 \mathrm{IU} / \mathrm{ml}$ insulin, $10 \mathrm{nM}$ dexamethasone, $25 \mathrm{mM}$ glucose, $100 \mathrm{U} / \mathrm{ml}$ penicillin $\mathrm{G}, 100 \mu \mathrm{g} / \mathrm{ml}$ streptomycin and $0.25 \mu \mathrm{g} / \mathrm{ml}$ amphotericin B. For each hepatocyte preparation, cell viability was checked by the exclusion of trypan blue.

\section{Cell culture and transient transfection}

Alexander cells (Human epithelial hepatoma cell lines; American Type Culture Collection number CRL-8024) were maintained as monolayer cultures and grown in Dulbecco's modified Eagle's medium (DMEM) (Invitrogen) supplemented with $10 \%(\mathrm{v} / \mathrm{v})$ fetal bovine serum, $100 \mathrm{U} / \mathrm{ml}$ penicillin, and $100 \mathrm{\mu g} / \mathrm{ml}$ streptomycin. Plasmid DNAs were purified using Qiagen Midiprep kit columns (Qiagen, Valencia, CA). Transient transfection and luciferase assays were performed as described previously (Cha et al., 2001). Briefly, cells were plated in six-well tissue culture plates at a density of $1 \times 10^{6}$ cells/well in $2 \mathrm{ml}$ of medium. After a $20 \mathrm{~h}$ attachment period, transfections with $0.5 \mu \mathrm{g}$ of each construct of GLUT2 promoter and control vector were performed with LipofectAMINE PLUS reagent (Life Technologies, Carlsbad, CA), according to the manufacturer's protocol. After $24 \mathrm{~h}$ transfection, the medium was replaced by a medium containing Wy $14,643(20 \mu \mathrm{M}$, final concentration), rosiglitazone (2 $\mu \mathrm{M}$, final concentration) and 9 -cis retinoic acid $(1 \mu \mathrm{M}$, final concentration) respectively. Cells were cultured further for $24 \mathrm{~h}$ and harvested in reporter lysis buffer (Promega). Luciferase data were expressed as luciferase activity corrected by $\beta$-galactosidase activity in the cell lysate. Each transfection was performed in triplicate and repeated three to five times.

\section{Nuclear extracts preparation}

Nuclear extract from liver of male Sprague-Dawley rats was prepared as described by Gorski et al. (Gorski et al., 1986). Protein concentration was determined by the method of Bradford (Bradford, 1976).

\section{Electrophoretic mobility shift assay (EMSA)}

The oligonucleotide probe GLUT2-PPRE was labeled as described previously (Kim et al., 2002b). Ten pmoles of single stranded sense oligonucleotide were labeled with $\left[\gamma^{32} \mathrm{P}\right]$ ATP using T4 polynucleotide kinase and annealed with 50 pmoles of unlabeled antisense oligonucleotides. The resulting double stranded oligonucleotides were purified by Sephadex G50 spin column. The labeled probe $(10,000 \mathrm{cpm})$ was incubated with $5 \mu \mathrm{g}$ of nuclear extract from rat liver for $30 \mathrm{~min}$ on ice. The binding reactions were same as described (Kim et al., 2000). To perform supershift 
assay, the binding mixtures were incubated for $10 \mathrm{~min}$ at room temperature in the presence of $1 \mu \mathrm{l}$ of antiPPAR $\gamma$ (Kim et al., 2002a). Protein-DNA complexes were resolved from the free probe by electrophoresis at $4{ }^{\circ} \mathrm{C}$ on a $4 \%$ polyacrylamide gel in $0.25 \times \mathrm{TBE}$ buffer $(1 \times$ TBE contained $9 \mathrm{mM}$ Tris, $90 \mathrm{mM}$ boric acid, $20 \mathrm{mM}$ EDTA, pH 8.0). The dried gels were exposed to $X$-ray film at $-70^{\circ} \mathrm{C}$ with an intensifying screen. The oligonucleotide sequences used in EMSA were as follows: GLUT2-PPRE, 5'-CTGTGCTCAAGC CACAAGTCATTGGGGTAAAGGGT-3'; mut1, 5'-CTG TGCTCAAG C CA C taccgtTTGG G TAAAGG GT-3'; mut2, 5'-CTGTGCTCAAGCCACAAGTCATtcagtgAAAGGGT-3'; mut1+2, 5'-CTGTGCTCAAGCCACtaccgtTtcagtgAAAGGGT-3'. Mutated bases are shown in lowercase letters. The oligonucleotide for CYP4A6-PPRE (PPRE of cytochrome p450 gene) (Muerhoff et al., 1992) was synthesized.

\section{Animals and drug administration}

5-week-old male ob/ob mice and lean littermates (Jackson Laboratories, Bar Harbor, ME) were housed in plastic cages on a 12:12 light/dark cycle with free access to water and food (Purina 5008). After 2 weeks of acclimation, animals were weighed, bled via the tail vein, and assigned to treatment groups based on starting glucose values (first criterion) and initial body weights (second criterion). Diabetes were confirmed (glucose level; $296 \mathrm{mg} / \mathrm{dl}$ ) by checking the plasma glucose levels. Before treatment of drug, oral glucose tolerance test (OGTT) was performed (0-day), and mice were gavaged once daily with vehicle, rosiglitazone $(30 \mathrm{mg} / \mathrm{kg}$ ) for 7 days (7-day). Animals were weighed and performed oral glucose tolerance test again. At the end of the experiments, animals were sacrificed by cervical dislocation under isoflurane anesthesia, and livers were rapidly excised, flash frozen in liquid nitrogen, and stored at $-70^{\circ} \mathrm{C}$ for RNA analysis.

\section{RNA preparation and reverse transcription- polymerase chain reaction (RT-PCR)}

Total RNA was isolated from primary hepatocytes using TRIzol reagent by manufacturer's protocol (Life Technologies). For RT-PCR, first strand cDNA was synthesized from $3 \mu \mathrm{g}$ of total RNA using random hexamer and Superscript II reverse transcriptase (Life Technologies). One $\mu \mathrm{l}$ of the reverse transcription reaction mixture was amplified with primers specific for GLUT2 and glyceraldehyde 3-phosphate dehydrogenase $(G 3 P D H)$ in the total volume of $50 \mu$ l. Linearity of the PCR was tested by amplification cycles between 20-30. According to test amplification profile, samples were amplified using the following parame-
A

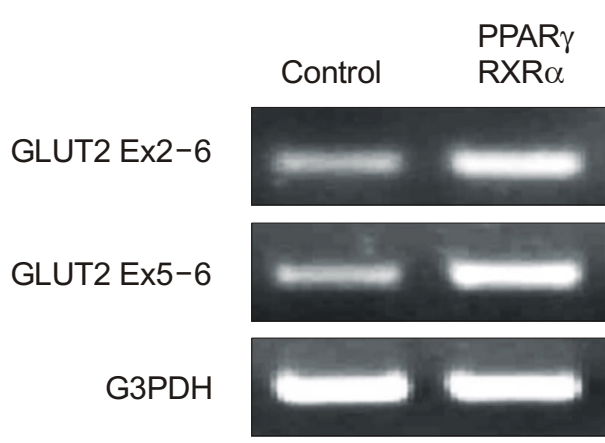

C

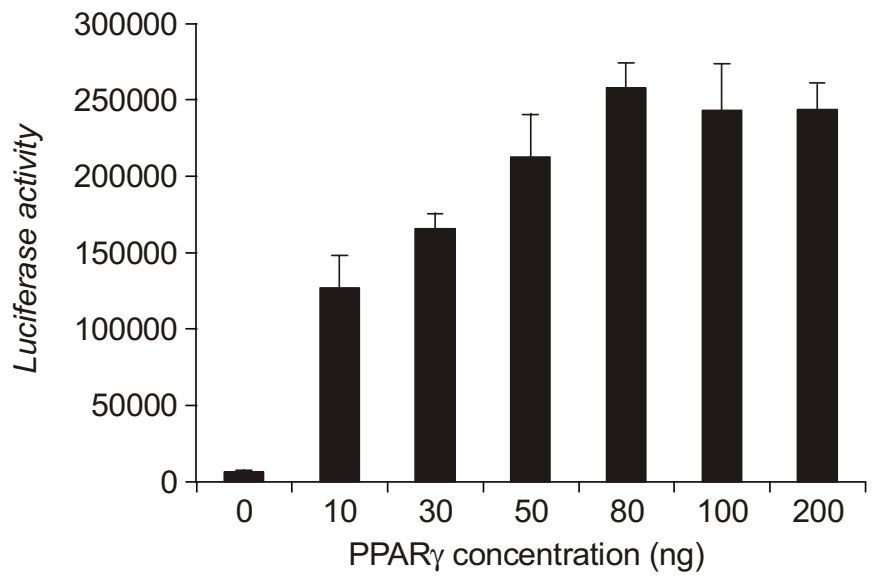

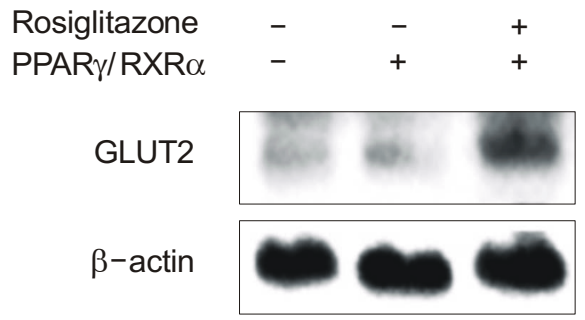

Figure 1. Effect of PPAR- $\gamma$ and PPAR- $\gamma$ ligands on the GLUT2 mRNA content. PGLM and PMGT2-1112 were cotransfected with $100 \mathrm{ng}$ of the indicated PPAR- $\gamma$ and 100 ng of RXR- $\alpha$ expression vectors into Alexander cell (A) and mouse primary hepatocytes (B). After trasfection, $2 \mu \mathrm{M}$ rosiglitazone and $1 \mu \mathrm{M} 9-C R$ for receptors were treated to Alexander cell and mouse primary hepatocytes maintained at $25 \mathrm{mM}$ glucose concentration for $24 \mathrm{~h}$. Total RNA was extracted for each group and subjected to RT-PCR (A) and Northern blot analysis (B). (C) Dose response activation of GLUT2 promoter construct by PPAR- $\gamma$ in Alexander cell. Ten to $200 \mathrm{ng}$ of PPAR- $\gamma$ and $100 \mathrm{ng}$ of RXR- $\alpha$ were used for transfection. The luciferase activities were normalized with respect to $\beta$-galactosidase activities. Results are the mean \pm S.D. of three independent experiments in triplicate. 
ters: $94^{\circ} \mathrm{C}$ for $30 \mathrm{~s}, 58^{\circ} \mathrm{C}$ for $30 \mathrm{~s}, 72^{\circ} \mathrm{C}$ for $30 \mathrm{~s}$. $\mathrm{G} 3 \mathrm{PDH}$ was used as an internal control for quality and quantity of RNA. Primers used in PCR were follows: GLUT2-Ex2-sense, 5'-ATCACCGGAACCTTGGCTTTCACT-3', GLUT2-Ex5-sense, 5'-GGCTAATTTCAGGACTGGTT-3'; GLUT2-Ex6R-antisense, 5'-TTTC TTTGCCCTGACTTCCT-3'; G3PDH-sense, 5'-ACCAC AGTCCATGCCATCAC-3'; G3PDH-antisense, 5'-TCC ACCACCCTGTTGCTGTA-3'.

\section{Northern blot hybridization of mRNA}

Aliquots of total RNA $(20 \mu \mathrm{g})$ from each sample were denatured with RNA sample loading buffer $(20 \mathrm{mM}$ MOPS, $\mathrm{pH}$ 7.0, $2 \mathrm{mM}$ sodium acetate, $1 \mathrm{mM}$ EDTA, $8 \%$ formaldehyde, $50 \%$ formamide), and subjected to electrophoresis in a $0.9 \%$ denaturing formaldehyde agarose gel, and transferred to Nylon membrane. The cDNA of mouse GLUT2 was labeled with $\left[\alpha-{ }^{32} P\right]$ dCTP using Rediprime Labeling Kit (Amersham Biosciences) and used as a probe. The membranes were hybridized with the probe for $2 \mathrm{~h}$ at $65^{\circ} \mathrm{C}$ with RapidHybrid buffer (Amersham Biosciences). After hybridization, the membrane was washed twice with high salt washing buffer $(0.1 \%$ SDS, $2 \times$ SSC $)$ at room temperature for $30 \mathrm{~min}$ followed by low salt washing buffer $(0.1 \%$ SDS, $0.1 \times \mathrm{SSC})$ at $65^{\circ} \mathrm{C}$ for $15 \mathrm{~min}$. The membrane was exposed to $X$-ray film with intensifying screen at $-70^{\circ} \mathrm{C}$.

\section{Chromatin immunoprecipitation (ChIP) assay}

The ChIP assay protocol was adapted from methods as described by Duong et al. (Duong et al., 2002). Adult male lean $(+/+)$ and diabetic (ob/ob) mice (blood glucose level; $>240 \mathrm{mg} / \mathrm{dl}$ ) had free access to $\mathrm{Pu}-$ rina chow. The livers were perfused with serum- free Dulbeco's modified Eagle's medium (DMEM) for 5 min and cross-linked with $5 \%$ formaldehyde in serum-free DMEM for $5 \mathrm{~min}$. The livers were homogenized, pelleted by centrifugation at $2000 \mathrm{rpm}$ for $4 \mathrm{~min}$ at $4^{\circ} \mathrm{C}$, and resuspended in SDS lysis buffer (1\% SDS, 10 $\mathrm{mM}$ EDTA, $50 \mathrm{mM}$ Tris-HCl, $\mathrm{pH}$ 8.0). The lysate was sonicated on ice for $3 \mathrm{~min}$ at a setting of cycle 0.8 , amplitude 80 and sheared to $100-600 \mathrm{bps}$. To provide a positive control (input) for each condition, one undiluted aliquot was retained for further processing in parallel with all the other samples at the reversal of cross-linking step. To reduce nonspecific background, each chromatin sample $(1 \mathrm{ml})$ was precleared with 60 $\mu$ l of protein A/G-agarose (Santa Cruz Biotech, CA), supplemented with $200 \mu \mathrm{g} / \mathrm{ml}$ sonicated salmon sperm DNA (Stratagene), and the beads were pelleted. Chromatin complexes in the supernatant were immunoprecipitated overnight at $4^{\circ} \mathrm{C}$ using $30 \mu \mathrm{g}$ of primary antibody, or without antibody. Immune complexes were collected with $60 \mu$ of protein A/G-agarose including $200 \mu \mathrm{g} / \mathrm{ml}$ of salmon sperm DNA. Promoter-specific PCR primers were as follows: GLUT2 promoter (sense, 5'-TGCCTCGGCTTCCACAAAAG3', antisense, 5'-GTGGATGAATAGCTGACCAG-3').

\section{Statistics}

All transfection studies were carried out in three separate experiments, where triplicate dishes were transfected. Data are expressed as means \pm S.D. Statistical analysis was carried out using Microsoft Excel software (Microsoft, Redmond, WA).

\section{Results}

\section{Effect of PPAR- $\gamma$ on the GLUT2 expression}

As shown in Figure 1A, RT-PCR of the exons of GLUT2 revealed that transfection of PPAR- $\gamma / \mathrm{RXR}-\alpha$ with rosiglitazone induced the GLUT2 expression when compared to untransfected Alexander cell line (control), whch was maintained at the $25 \mathrm{mM}$ glucose concentration. Northern blot analysis showed that GLUT2 expression was not increased by Wy14,643/ 9 -cis retinoic acid treatment at $25 \mathrm{mM}$ glucose concentration in mouse primary hepatocytes (data not shown). However, Rosiglitazone/9-cis retinoic acid treatment induced GLUT2 mRNA level. GLUT2 mRNA was not increased by transfecting PPAR- $\gamma / \mathrm{RXR}-\alpha$ when their ligands were not added to the culture me-

A

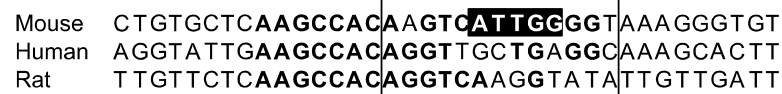

B

\begin{tabular}{llllll} 
Human & -1125 & +1 & LUC & pHGT2 \\
Mouse & -1112 & +1 & LUC & pMGT2 \\
\cline { 2 - 3 } Rat & -910 & +1 & LUC & pRGT2
\end{tabular}

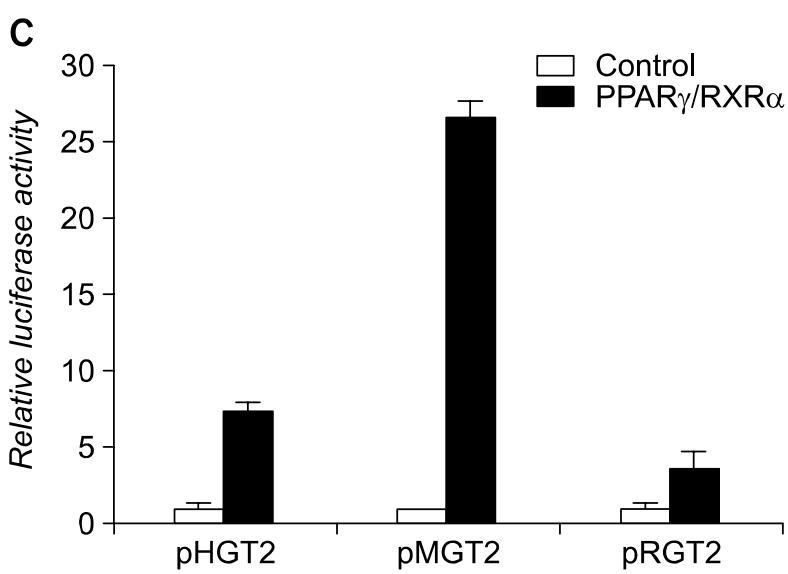

Figure 2. GLUT2 promoters are responding to PPAR- $\gamma$. (A) Sequence comparison of the proximal region of GLUT2 gene. (B) Schematic diagram of GLUT2 promoter constructs from human, mouse, and rat. (C) Responsiveness of GLUT2 promoter constructs to PPAR- $\gamma$. Detailed experimental conditions are the same as described in Figure1. 
dium (Figure 1B). To determine whether PPAR- $\gamma$ regulates GLUT2 promoter activity, we constructed mouse GLUT2 promoter construct (pmGT2-1112) and observed their responsiveness (Figure $1 \mathrm{C}$ ). The GLUT2 promoter construct was activated by transfected PPAR- $\gamma$ expression vector from $10 \mathrm{ng}$ to $80 \mathrm{ng}$ ) in a dose dependent manner, suggesting that the promoter is responding to PPAR- $\gamma$ specifically (Figure 1C).

\section{Localization and identification of PPRE in the GLUT2 promoter}

Figure $2 \mathrm{~A}$ shows the sequence comparison of the proximal regions of GLUT2 gene between species. Unlike human and rat GLUT2 promoter, mouse promoter seems to contain NF-Y binding sites in the $D R+1$ consensus sequence (Boxed region). For the comparison of the GLUT2 promoter activity to PPAR- $\gamma$, part of the proximal regions of GLUT2 gene was subcloned into luciferase vector (Figure 2B) and named pHGT2 (human), pMGT2 (mouse), and pRGT2 (rat), respectively. As shown in figure $2 \mathrm{C}$, all the constructs showed good responsiveness to PPAR- $\gamma$ and pMGT2 showed the strongest promoter activity. To identify and characterize a functional PPRE involved in regulating the mouse GLUT2 promoter activity, we generated serially deleted 5 ' flanking regions (from $-1112,-890,389,-283,-166$, and -57 to +1$)$ and truncated PPRE (-283/-166) in PMGT2d-389 and examined their responsiveness to PPAR- $\gamma$ in Alexander cells (Figure 3A). The promoter activity was well maintained down to -283 region. Further deletion to -166 region resulted in a dramatic drop in the luciferase activity which was assayed in Alexander cell line (Figure 3B) and primary hepatocytes (Figure 3C), suggesting that the PPRE might be present between -283 and -166 . Internal deletion between -283 and -166 also diminished the promoter activity (Figure 3B). Computer-based analysis of the sequence sug-
A

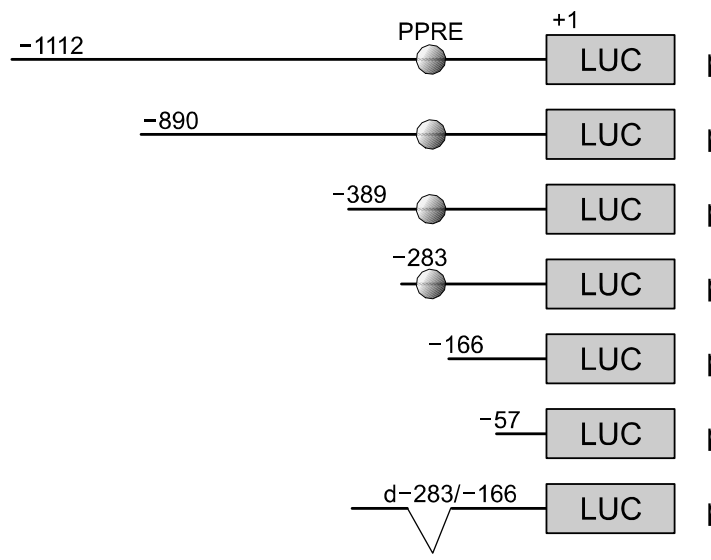

B

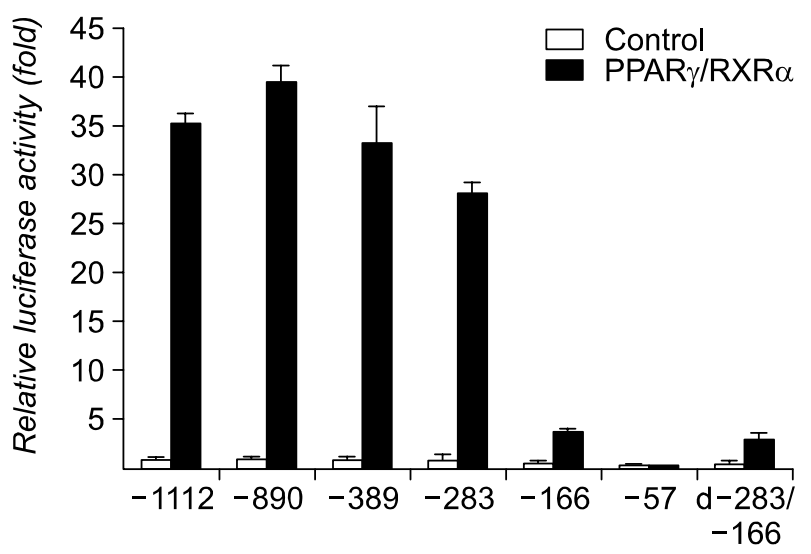

PMGT2-1112

PMGT2d-890

PMGT2d-389

pMGT2d-283

PMGT2d-166

pMGT2d-57

pMGT2d-283/-166

Figure 3. Localization of PPRE in the mouse GLUT2 promoter. (A) Structure of serial deletion and internal deletion (d-283/-166) constructs of PMGT2-1112. The indicated numbers represent bases from ATG codon as +1 . Cells were cotransfected with each luciferase construct with or without PPAR- $\gamma /$ RXR- $\alpha$ expression plasmids into Alexander cell (B) or mouse primary hepatocytes (C). All results were normalized with respect to $\beta$-galactosidase activities and were shown as relative fold increase in the luciferase activities compared to those of control. Normalized luciferase activities are shown as means \pm S.D. of three independent experiments in triplicate. 
A
$\mathrm{DR}+1$$$
-211
$$
AGGTCANAGGTCA
GLUT2-PPRE
CTGTGCTCAAGCCACAAGT CATTGGGGTAAAGGGT
mut 1 CTGTGCTCAAGCCACT A CCGT TTGGGGT AAAGGGT
mut 2 CTGTGCTCAAGCCACAAGTCA TTCAGT GAAAGGGT
mut $1+2$ CTGTGCTCAAGCCACT ACCGT T TCAGT GAAGGGT

\section{NFY}

B

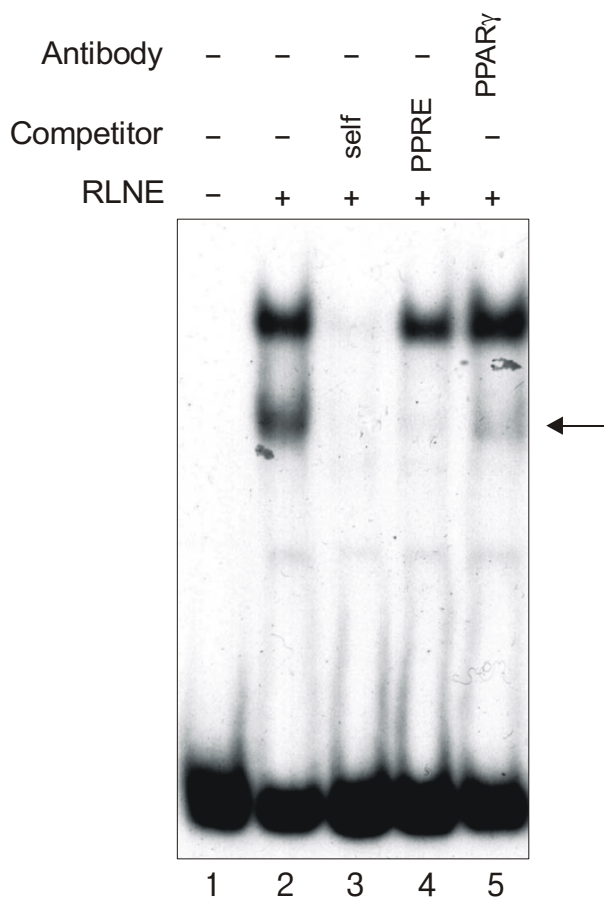

C

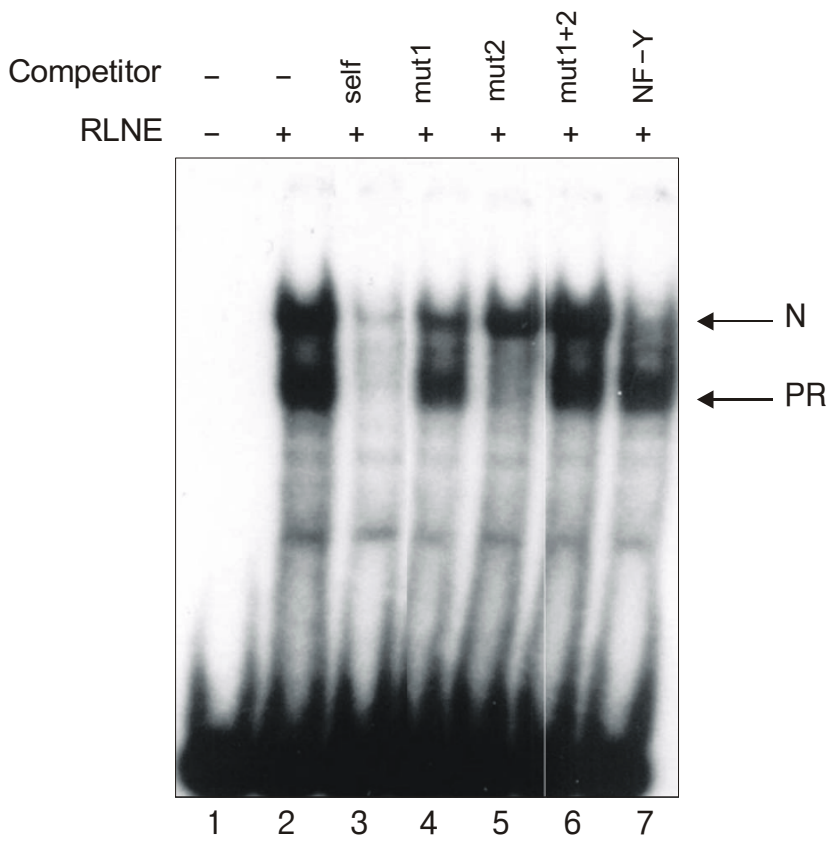

Figure 4. Effect of mutation at the putative PPRE of GLUT2 promoter. (A) Sequences of wild type (GLUT2-PPRE) and mutated oligonucleotides (mut1, mut2, and mut1+2) are shown. Putative GLUT2 PPRE sequence is compared with conventional DR+1. The mutated bases were represented by bold characters. Putative NF-Y consensus sequence is indicated by gray box. (B) EMSA of GLUT2-PPRE (from -211 bp to -177 bp) using rat nuclear extract. Thirty pmoles of $\left.{ }^{32} \mathrm{P}\right]$-labeled double-stranded oligonucleotide were incubated with $5 \mu \mathrm{g}$ of rat liver nuclear extracts (RLNE) in the presence of 100 -fold molar excess of the indicated cold competitors. For the supershift assay, $1 \mu \mathrm{g}$ of anti-PPAR- $\gamma$ antibody was used. Competitors are as follows: self; GLUT2-PPRE, PPRE; PPRE consensus sequence of CYP4A6 gene. The DNA-protein complexes are indicated by arrow. (C) Effect of mutation on the protein binding. Mutant probes and NF-Y consensus sequence were used as competitors. N; NF-Y, PR: PPAR/RXR- $\alpha$ complex.

gested that the region between -206 and -147 may contain a putative $\mathrm{DR}+1$ element which is known to bind PPAR isoforms (Figure 2A). The binding of PPAR isoforms to putative GLUT2-PPRE was analyzed by EMSA using rat liver nuclear extract. Figure $4 \mathrm{~A}$ shows the putative $\mathrm{DR}+1$ sequence as well as NF-Y binding sites overlapped with $D R+1$ in the GLUT2 promoter. EMSA experiment using rat liver nuclear extract showed that faster moving proteinDNA complex (lower band) could be PPAR- $\gamma$ because unlabeled CYP4A6-PPRE (Muerhoff et al., 1992) efficiently competed with PPARs/RXR- $\alpha$ complex formation (Figure 4B, lane 4) and the complex was supershifted by PPAR- $\gamma$ antibody (Figure 4B, lane 5).
To confirm the PPAR- $\gamma$ binding sequence, competition assay using mutant versions (mut1, mut2, and mut $1+2$, Figure $4 A$ ) of putative PPRE were performed (Figure 4C). Mut1+2 lost the ability to compete the formation of faster and slower DNA-protein complex (lane 6) whereas mut1 did not compete the formation of faster complex (lane 4) suggesting that mut1 region is critical for PPAR binding. Mut2 did not compete the formation of slower complex (lane 5) when compared to mut1. Instead, the slowly migrating band was competed by NF-Y consensus sequence (Figure 4C, lane 7) (Raymondjean et al., 1991) and the addition of mut2 to reaction mixture failed to compete the slowly migrating DNA complex (Figure 4C, lanes 5). These 
A

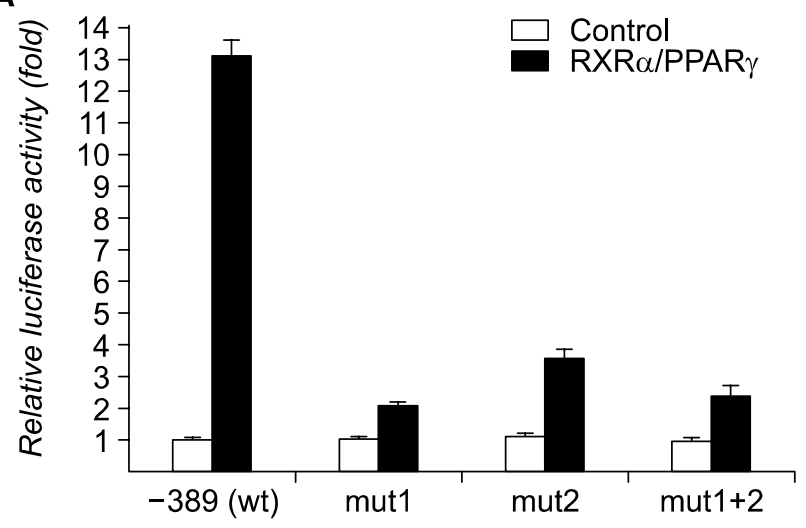

B

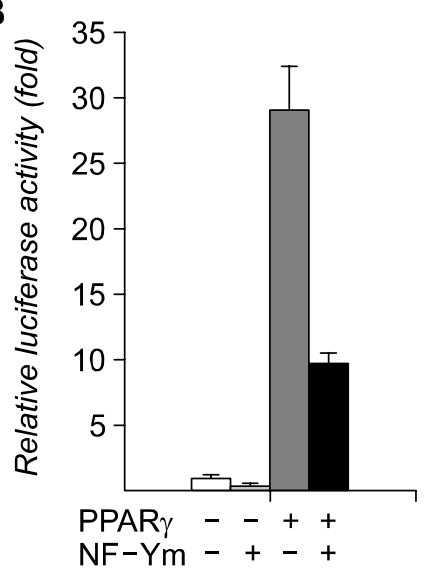

Figure 5. Effect of mutation on the GLUT2 promoter activity in the Alexander cells. (A) mut1, mut2, and mut1+2 were generated from pMGT2d-389 (wt) using site-directed mutagenesis. The reporter constructs containing a wild and mutant sequence of mouse GLUT2 promoter were transfected with or without expression vectors of PPAR- $\gamma$ and $R X R-\alpha .2 \mu \mathrm{M}$ rosiglitazone and $1 \mu \mathrm{M} 9-C R$ ligands for receptors were treated after transfection. (B) Role of NF-Y on the PPAR- $\gamma$ driven GLUT2 promoter activity. The wild type pMGT2-1112 reporter construct was transfected into Alexander cells with or without expression vectors of PPAR- $\gamma / R X R-\alpha$ and NF-Ym as indicated. All results were normalized with respect to $\beta$-galactosidase activities. The results were shown as relative fold increase of luciferase activities compared to those of control. Results are the mean \pm S.D. of three independent experiments in triplicate.

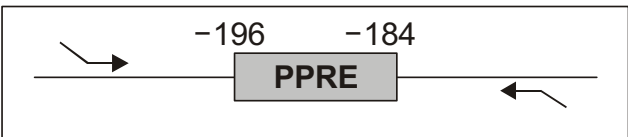

Antibodies

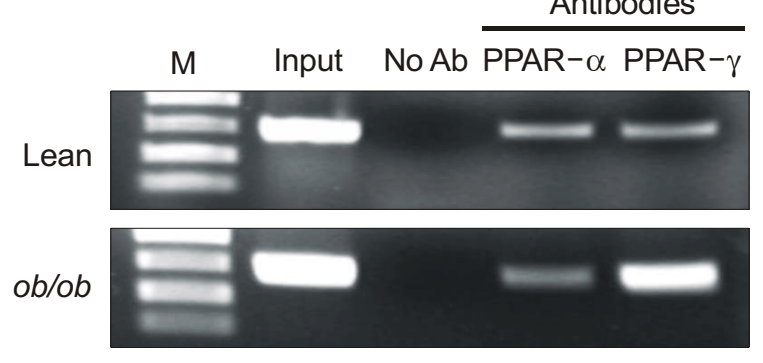

Figure 6. Chromatin immunoprecipitation (ChIP) assay. Equivalent amounts of DNA extracted from chromatin from lean and ob/ob mice, and chromatin were precipitated using $1 \mu \mathrm{g}$ of PPAR- $\alpha$ or PPAR- $\gamma$ antibody. The GLUT2-PPRE (-196/-184 bp) region was amplified by PCR. In order to normalize the amount of chromosomal DNA used in immunoprecipitation between groups, input chromatin (one hundredth of chromosomal DNA used for immunoprecipitation) was also used. Detailed PCR conditions and methods of sample treatment were described in the 'Materials and Methods'. M, Marker.

data indicate, that NF-Y as well as RXR- $\alpha$, a heteromeric partner of PPAR isoforms, may bind to the region (Figure $4 \mathrm{~A})$. The luciferase assay suggested the relative importance of mut1 and mut2 (Figure $5 \mathrm{~A}$ ). Both mut1 and mut1+2 showed reduced promoter activity, suggesting that mut1 region is important in PPAR- $\gamma$ driven promoter activity. Mut2 region that contains NF-Y binding site may help exert promoter activity driven by PPAR $-\gamma$. This was further confirmed by addition of dominant negative form of NF-Y (NF$Y \mathrm{~m})$ which caused decreased PPAR- $\gamma$ driven promoter activity (Figure 5B).

The binding of PPAR- $\gamma$ to the GLUT2 promoter was increased in the liver of $o b / o b$ mice

If the GLUT2 expression by PPAR- $\gamma$ was activated in diabetic states, the physical contact between PPAR- $\gamma$ and a putative PPRE in the GLUT2 promoter should be confirmed. To address this question, we performed chromatin immunoprecipitation assay (ChIP assay) using lean and ob/ob mice. As shown in Figure 6, PPAR $-\alpha$ and PPAR- $\gamma$ bind to GLUT2-PPRE very weakly in the lean mice. However, the binding of PPAR- $\gamma$ to the putative PPRE (-196/-84) on the GLUT2 promoter was increased in ob/ob mice, whereas the binding of PPAR- $\alpha$ was not increased, indicating that PPAR- $\gamma$ may play a role as an activator of the GLUT2 gene expression in liver.

\section{Discussion}

PPAR- $\gamma$ is more abundant in adipose tissue than in liver, or muscle (Tontonoz et al., 1994; Braissant et al., 1996). However, improvement in glucose homeostasis by PPAR- $\gamma$ ligand treatment involves insulin sensitization in muscle and liver (Inzucchi et al., 1998). Molecular mechanism of actions of TZDs in the glucose homeostasis occurring in tissues other than adipose tissues remains elusive. Direct effects of TZDs on glucose uptake in L6 myotubes have been identified (Ciaraldi et al., 1990; Zhang et al., 1994), which is supported by increased activity of the glucose transporter GLUT4 and of PI-3-kinase (Yone- 
mitsu et al., 2001). On the other hand, PPAR- $\gamma$ stimulated the promoter activity of genes responsible for glucose sensing apparatus of pancreatic $\beta$-cells, suggesting that this ligand could also improve glucosestimulated insulin secretion (Kim et al., 2000; 2002b).

In the hyperglycemic states of type 2 diabetes, administration of TZDs causes amelioration of blood glucose level, suggesting that the liver glucose sensor can be a direct target of TZDs action. Previously, we have shown that LGK is transcriptionally activated by TZDs in liver (Kim et al., 2004). In parallel with this observation, we have explored a possibility that one of the partner protein, GLUT2, of hepatic glucose sensor could be a transcriptional target of TZDs action in liver.

In this study, we have identified and localized the PPRE (-197 and $-184 \mathrm{bp})$ in the region of mouse GLUT2 promoter. The mouse region is similar to authentic DR+1 sequence (Palmer et al., 1995), and activated by TZDs treatment. Currently, the contribution of PPAR- $\gamma$ in hepatic gene regulation in physiological state is challenged by the limited expression of PPAR- $\gamma$ compared to that of PPAR- $\alpha$ (Way et al., 2001). However, in pathological state of type 2 diabetes or severe obesity, the liver was shown to overexpress PPAR- $\gamma$ isoforms (Rahimian et al., 2001). Thus, the GLUT2 expression in liver could be activated by TZDs in the type 2 diabetes patients. Even in the pathological conditions, PPAR $\alpha$ is more abundant than PPAR- $\gamma$. The DR+1 sequence in the GLUT2 may bind either PPAR- $\alpha / R X R-\alpha$ or PPAR- $\gamma / R X R-\alpha$. Then, why PPAR- $\alpha / R X R-\alpha$ cannot activate the GLUT2 promoter? And, how the PPAR- $\gamma / R X R-\alpha$ can activate the GLUT2 promoter? To address these questions, we have performed the ChIP assay using mouse GLUT2 promoter. As shown, the binding of PPAR- $\gamma$ to GLUT2 promoter is increased in the ob/ob mice, where PPAR- $\gamma$ is overexpressed. From this experiment, it is concluded that the binding of PPAR- $\gamma$ to GLUT2 promoter is increased in the diabetic or obese mice, where PPAR- $\gamma$ is known to be overexpressed.

EMSA study suggested that mut1 and mut2 might constitute DR+1 site. However, competition and supershift experiment showed that the slow migrating band (upper band, Figure 4C) contains NF-Y. NF-Y binds CCAAT boxes located within 100 bp upstream from the transcription start sites, and these elements are known to be important for early functions in the formation of preinitiation complex (Dorn et al., 1987; Milos et al., 1992). NF-Y also has been reported to interact with transcription factors binding to upstream promoter cis-elements of gene. Among several CCAATbinding proteins including $\mathrm{Y}$-box factors, CTF/NF-1, NF-Y and C/EBP, NF-Y is the most ubiquitous and specific key proximal promoter factor in the transcriptional regulation of different eukaryotic genes. Unlike other CCAAT-binding proteins, NF-Y has an absolute requirement of CCAAT pentanucleotide as well as a strong preference for specific flanking sequences (Matuoka et al., 1999). The mechanism of regulating the expression of these genes cannot be simply due to NF-Y DNA binding. It is likely that ad- ditional factors might be involved in the action of NF-Y. Indeed, previous studies from other groups have suggested that NF-Y interacts, either functionally or physically, with other transcription factors or $n$ uclear proteins both in vitro and in vivo (Framson et al., 1993; Zwicker et al., 1995; Ericsson et al., 1996). In this system, the contribution of NF-Y transacting factor to PPAR- $\gamma$ action was confirmed by the addition of dominant negative form of NF-Y (NF-Ym), which reduced the promoter activity by $65 \%$. The contribution of NF-Y to other transcription factors has been reported (Lee et al., 2003). However, a molecular mechanism or interaction between NF-Y and transacting factors needs to be explored.

In conclusion, we have identified a functional PPRE in the GLUT2 promoter in liver, and showed that PPAR- $\gamma$ could bind to this element, and increased the transcription of GLUT2 mRNA in the ob/ob mice where appropriate amount of PPAR- $\gamma$ is expressed. Thus, it is assumed that PPAR- $\gamma$ may have a direct activating role for the hepatic GLUT2 and LGK (Kim et al., 2004), which help the transport of glucose into hepatocytes.

\section{Acknowledgment}

This work was supported by grant from Korea Science and Engineering Foundation (KOSEF) [1999-2207-008-3] and a grant [R13-2002-054-01001-0 (2002)] from the Basic Research Program of the Korea Science and Engineering Foundation.

\section{References}

Barroso I, Gurnell M, Crowley VE, Agostini M, Schwabe JW, Soos MA, Maslen GL, Williams TD, Lewis H, Schafer AJ, Chatterjee VK, O'Rahilly S. Dominant negative mutations in human PPARgamma associated with severe insulin resistance, diabetes mellitus and hypertension. Nature 1999;402: 880-3

Bradford MM. A rapid and sensitive method for the quantitation of microgram quantities of protein utilizing the principle of protein-dye binding. Anal Biochem 1976;72:248-54

Braissant O, Foufelle F, Scotto C, Dauca M, Wahli W. Differential expression of peroxisome proliferator-activated receptors (PPARs): tissue distribution of PPAR-alpha, -beta, and -gamma in the adult rat. Endocrinology 1996;137:354-66

Cavaghan MK, Ehrmann DA, Byrne MM, Polonsky KS. Treatment with the oral antidiabetic agent troglitazone improves beta cell responses to glucose in subjects with impaired glucose tolerance. J Clin Invest 1997;100:530-7

Cha JY, Kim HI, Im SS, Li TZ, Ahn YH. HNF1 and/or HNF3 may contribute to the tissue specific expression of glucokinase gene. Exp Mol Med 2001;33:59-63

Ciaraldi TP, Gilmore A, Olefsky JM, Goldberg M, Heidenreich KA. In vitro studies on the action of CS-045, a new antidiabetic agent. Metabolism 1990;39:1056-62

Dorn A, Bollekens J, Staub A, Benoist C, Mathis D. A 
multiplicity of CCAAT box-binding proteins. Cell 1987;50: 863-72

Duong DT, Waltner-Law ME, Sears R, Sealy L, Granner DK. Insulin inhibits hepatocellular glucose production by utilizing liver-enriched transcriptional inhibitory protein to disrupt the association of CREB-binding protein and RNA polymerase II with the phosphoenolpyruvate carboxykinase gene promoter. J Biol Chem 2002;277:32234-42

Edvardsson U, Bergstrom M, Alexandersson M, Bamberg K, Ljung B, Dahllof B. Rosiglitazone (BRL49653), a PPAR gamma-selective agonist, causes peroxisome proliferator-like liver effects in obese mice. J Lipid Res 1999;40:1177-84

Ericsson J, Jackson SM, Edwards PA. Synergistic binding of sterol regulatory element-binding protein and NF-Y to the farnesyl diphosphate synthase promoter is critical for sterolregulated expression of the gene. J Biol Chem 1996;271: 24359-64

Framson $\mathrm{P}$, Bornstein $\mathrm{P}$. A serum response element and a binding site for NF-Y mediate the serum response of the human thrombospondin 1 gene. J Biol Chem 1993;268:498996

Gorski K, Carneiro M, Schibler U. Tissue-specific in vitro transcription from the mouse albumin promoter. Cell 1986; 47:767-76

Guillemain G, Loizeau M, Pincon-Raymond M, Girard J, Leturque A. The large intracytoplasmic loop of the glucose transporter GLUT2 is involved in glucose signaling in hepatic cells. J Cell Sci 2000;113(Pt 5):841-7

Gurtner A, Manni I, Fuschi P, Mantovani R, Guadagni F, Sacchi A, Piaggio G. Requirement for down-regulation of the CCAAT-binding activity of the NF-Y transcription factor during skeletal muscle differentiation. Mol Biol Cell 2003;14:270615

He W, Barak Y, Hevener A, Olson P, Liao D, Le J, Nelson M, Ong E, Olefsky JM, Evans RM. Adipose-specific peroxisome proliferator-activated receptor gamma knockout causes insulin resistance in fat and liver but not in muscle. Proc Natl Acad Sci USA 2003;100:15712-7

Inzucchi SE, Maggs DG, Spollett GR, Page SL, Rife FS, Walton V, Shulman GI. Efficacy and metabolic effects of metformin and troglitazone in type II diabetes mellitus. N Engl J Med 1998;338:867-72

Jiang G, Dallas-Yang Q, Li Z, Szalkowski D, Liu F, Shen $X$, Wu M, Zhou G, Doebber T, Berger J, Moller DE, Zhang BB. Potentiation of insulin signaling in tissues of Zucker obese rats after acute and long-term treatment with PPARgamma agonists. Diabetes 2002;51:2412-9

Kim HI, Kim JW, Kim SH, Cha JY, Kim KS, Ahn YH. Identification and functional characterization of the peroxisomal proliferator response element in rat GLUT2 promoter. Diabetes 2000;49:1517-24

Kim HI, Cha JY, Kim SY, Kim JW, Roh KJ, Seong JK, Lee NT, Choi KY, Kim KS, Ahn YH. Peroxisomal proliferatoractivated receptor-gamma upregulates glucokinase gene expression in beta-cells. Diabetes 2002a;51:676-85

Kim JW, Ahn YH. C/EBP binding activity to site $F$ of the rat GLUT2 glucose transporter gene promoter is attenuated by c-Jun in vitro. Exp Mol Med 2002b;34:379-84

Kim SY, Kim HI, Park SK, Im SS, Li T, Cheon HG, Ahn $\mathrm{YH}$. Liver glucokinase can be activated by peroxisome proliferator-activated receptor-gamma. Diabetes 2004;53 Suppl 1:S66-70

Kliewer SA, Forman BM, Blumberg B, Ong ES, Borgmeyer $\mathrm{U}$, Mangelsdorf DJ, Umesono K, Evans RM. Differential expression and activation of a family of murine peroxisome proliferator-activated receptors. Proc Natl Acad Sci USA 1994;91:7355-9

Lee MG, Pedersen PL. Glucose metabolism in cancer: importance of transcription factor-DNA interactions within a short segment of the proximal region og the type II hexokinase promoter. J Biol Chem 2003;278:41047-58

Mangelsdorf DJ, Borgmeyer U, Heyman RA, Zhou JY, Ong $E S$, Oro AE, Kakizuka A, Evans RM. Characterization of three RXR genes that mediate the action of 9-cis retinoic acid. Genes Dev 1992;6:329-44

Matuoka K, Yu Chen K. Nuclear factor Y (NF-Y) and cellular senescence. Exp Cell Res 1999;253:365-71

Milos PM, Zaret KS. A ubiquitous factor is required for C/EBP-related proteins to form stable transcription complexes on an albumin promoter segment in vitro. Genes Dev 1992; 6:991-1004

Muerhoff AS, Griffin KJ, Johnson EF. The peroxisome proliferator-activated receptor mediates the induction of CYP4A6, a cytochrome P450 fatty acid omega-hydroxylase, by clofibric acid. J Biol Chem 1992;267:19051-3

Palmer CN, Hsu MH, Griffin HJ, Johnson EF. Novel sequence determinants in peroxisome proliferator signaling. $\mathrm{J}$ Biol Chem 1995;270:16114-21

Picard F, Auwerx J. PPAR(gamma) and glucose homeostasis. Annu Rev Nutr 2002;22:167-97

Rahimian R, Masih-Khan E, Lo M, Van Breemen C, Mcmanus BM, Dube GP. Hepatic over-expression of peroxisome proliferator activated receptor gamma2 in the ob/ob mouse model of non-insulin dependent diabetes mellitus. Mol Cell Biochem 2001;224:29-37

Raymondjean M, Pichard AL, Gregori C, Ginot F, Kahn A. Interplay of an original combination of factors: C/EBP, NFY, HNF3, and HNF1 in the rat aldolase $B$ gene promoter. Nucleic Acids Res 1991;19:6145-53

Seglen PO. Preparation of rat liver cells. I. Effect of $\mathrm{Ca} 2+$ on enzymatic dispersion of isolated, perfused liver. Exp Cell Res 1972;74:450-4

Sher T, Yi HF, Mcbride OW, Gonzalez FJ. cDNA cloning, chromosomal mapping, and functional characterization of the human peroxisome proliferator activated receptor. Biochemistry 1993;32:5598-604

Spiegelman BM. PPAR-gamma: adipogenic regulator and thiazolidinedione receptor. Diabetes 1998:47:507-14

Tontonoz P, Hu E, Graves RA, Budavari Al, Spiegelman BM. mPPAR gamma 2: tissue-specific regulator of an adipocyte enhancer. Genes Dev 1994:8:1224-34

Way JM, Harrington WW, Brown KK, Gottschalk WK, Sund- 
seth SS, Mansfield TA, Ramachandran RK, Willson TM, Kliewer SA. Comprehensive messenger ribonucleic acid profiling reveals that peroxisome proliferator-activated receptor gamma activation has coordinate effects on gene expression in multiple insulin-sensitive tissues. Endocrinology 2001;142: 1269-77

Yonemitsu S, Nishimura $\mathrm{H}$, Shintani $\mathrm{M}$, Inoue R, Yamamoto Y, Masuzaki H, Ogawa Y, Hosoda K, Inoue G, Hayashi T, Nakao K. Troglitazone induces GLUT4 translocation in L6 myotubes. Diabetes 2001;50:1093-101
Zhang B, Szalkowski D, Diaz E, Hayes N, Smith R, Berger J. Potentiation of insulin stimulation of phosphatidylinositol 3-kinase by thiazolidinedione-derived antidiabetic agents in Chinese hamster ovary cells expressing human insulin receptors and L6 myotubes. J Biol Chem 1994;269:25735-41

Zwicker J, Gross C, Lucibello FC, Truss M, Ehlert F, Engeland K, Muller R. Cell cycle regulation of cdc25C transcription is mediated by the periodic repression of the glutamine-rich activators NF-Y and Sp1. Nucleic Acids Res 1995;23:3822-30 